\title{
Variation in Selection Intensities among the Western Coastal Populations of India
}

\author{
A. K. Kapoor ${ }^{1} \&$ Monika Saini ${ }^{2}$ \\ ${ }^{1}$ Department of Anthropology, University of Delhi \\ 2 Department of Social Sciences, National Institute of Health and Family Welfare, New Delhi \\ * Corresponding author: drmonika@nihfw.org
}

Received August 315t, 2021

Accepted for publication October $15^{\text {th }}, 2021$

Online First October $15^{\text {th }}, 2021$

Keywords: Coastal, Embryonic, Fertility, Mortality, Post-natal, Pre-natal, Selection

\section{Abstract}

Selection is continuously occurring on the living beings and the fittest who are able to reproduce will survive. To measure this selection, the data from 954 women was obtained who belong to different ethnic groups of Gujarat and Maharashtra and various index and components were computed using Crow's Index and Johnston and Kensinger's Index. The Crow's total index value was found to be 0.539 . The mortality component was found to be 0.130 and fertility component was found

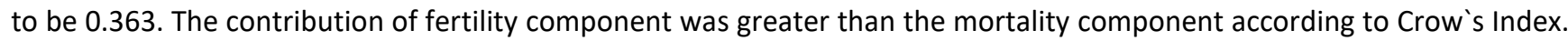
Value of total selection index computed using Johnston and Kensinger's Index is 0.639 . The index of selection due to prenatal mortality and post-natal mortality was observed to be 0.064 and 0.130 respectively. Therefore, it is found that among coastal populations of Gujarat and Maharashtra the selection trend is more due to fertility component than mortality component.

\section{Introduction}

Ever since Darwin, the role of natural selection in shaping the various characteristics of life and reproduction across different generations has been central to understanding variation in life and its extent. Natural selection is one of the major forces which cause changes in the genotypic frequencies of a population. Researches have proved that it is a natural force which increases the chance of survival of the fittest and adaptable ones.

Karl Pearson in 1907, examined that Darwinian Theory has application to civilised man and the heavy exemption from life does not means inefficiency (Pearson, 1912). Fitness is important demographic property, a function of reproduction and deaths variables in a population. It has been found that reproductive success in humans depends upon the total amount of progeny that parents contribute to the proceeding generations (Jacquard, 1969). In larger populations, there is a larger gene pool, meaning that it would take more time for natural selection to show its affect and cause fixation of alleles than in a smaller population. However, it is difficult to show direct evidence of such selection by experiments and to measure selection intensity directly. Natural selection does not only depend on the fluctuating fertility, but also depends upon the differential survival of the offsprings up to the reproductive age (Reddy et.al., 1987; Lasker \& Kaplan, 1995).

To measure the natural selection effect and its impact, Crow (1958) has provided an index to measure intensity of selection. This index mainly depends on two components first is Intensity of fertility (If) and second is Intensity of mortality $(\mathrm{Im})$. So, this index allows the changes in the fitness to be determined by calculating specific birth and death rates. The Crow index would measure actual selection only, if there is complete heritability and genetic factor solely determine birth and death rate (Jorde and Durbize, 1986), whereas 
index of value zero indicates no changes in fitness (Livingston and Spuhler, 1965). Later on, this index was improvised by Johnston and Kensinger (Johnston and kensinger, 1971) to measure the third component called prenatal mortality and this index is known as Johnston and Kensinger Index.

Worldwide study on natural selection have shown that socio-economic and socio-cultural environment of a population have major impact on the fertility and mortality components and afterwards on selection (Crow 1958; Spuhler 1962; Johnston and Kensinger 1971; Tripp- Reimer 1980; Jorde and Durbize 1986; Sarkar et al. 1994; Kapoor et al. 2003; Gautam, 2009).

In India, the studies over different population groups have shown that natural selection is playing an important role in demonstrating fertility and mortality differentials among different populations in various environments (Gosh 1970; Murthy and Ramesh 1978; Basu et al. 1988; Barua 1976; Kapoor and Patra 1998; Chengal Reddy and Lakshanudu 1979; Kapoor and kshatriya 2000; Rao and Murty 1984; Gautam 2006, 2009; Reddy and Chopra 1990). India also has a huge coastal boundary divided into Eastern Coastal Zone and Western Coastal Zone with a varying risk factor like cyclone, tsunami, flooding etc. The coastal vulnerability is induced both by human related causes like rise in greenhouse gas (Nicholls et al. 1999; Varekamp 1999) and natural factors like season change. So far, the study among the coastal part of India (Odisha and Goa) is conducted by Kapoor et al. in 2012 which reveals that mortality is predominant factor contributing to selection intensity among coastal populations (Kapoor et al., 2012) whereas fertility is predominant factor among Non-coastal populations (Singh and Kapoor, 2015). Hence, the present investigation was to determine the variation in selection intensities among populations of two states of western coast of India i.e., Gujarat and Maharashtra. This study will also supplement the previous study among the various coastal populations of India and the world.

\section{Methodology}

The data for the present study was collected in different phases during year 2017 to 2019, from 81 villages of Gujarat and Maharashtra. These villages

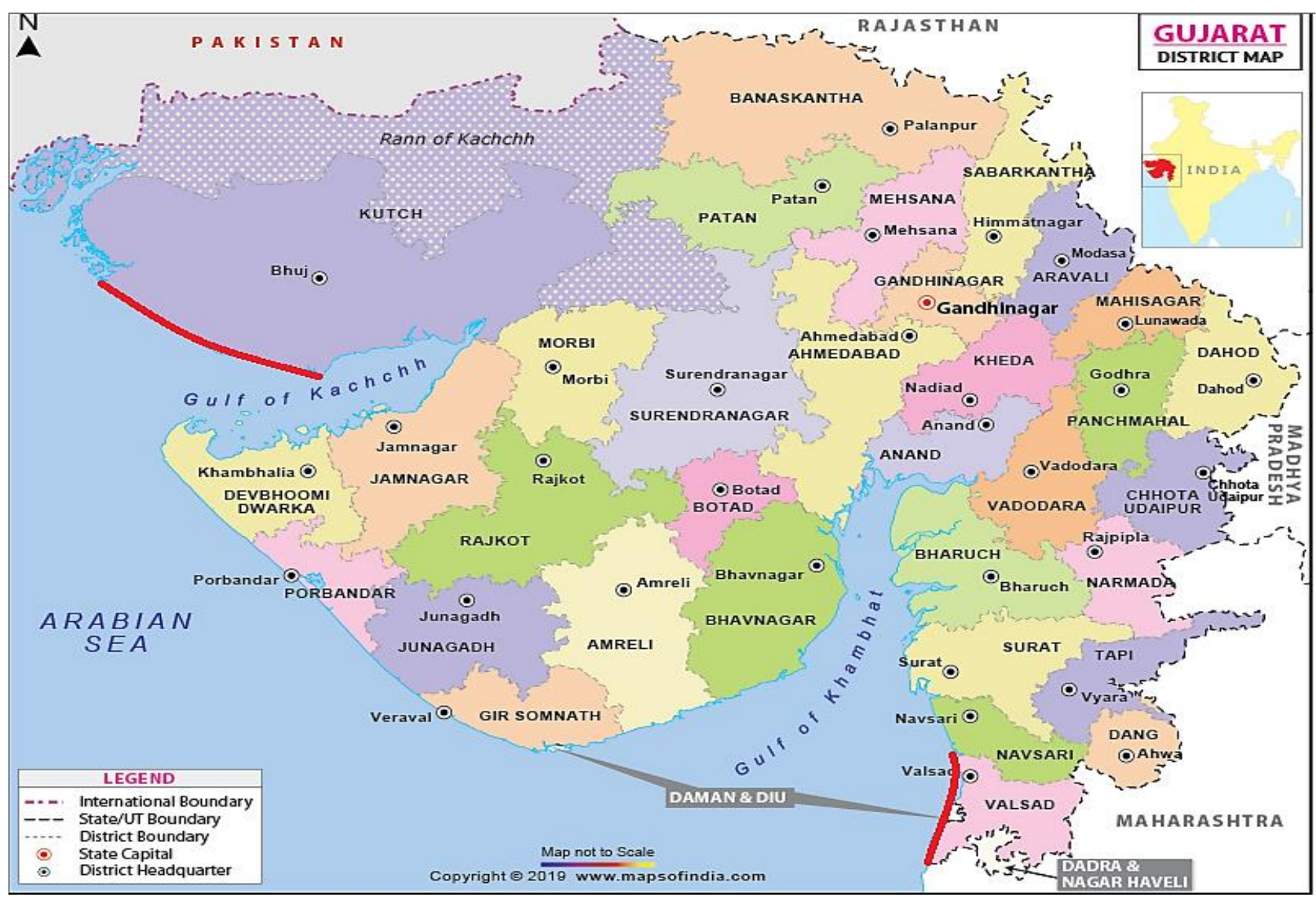




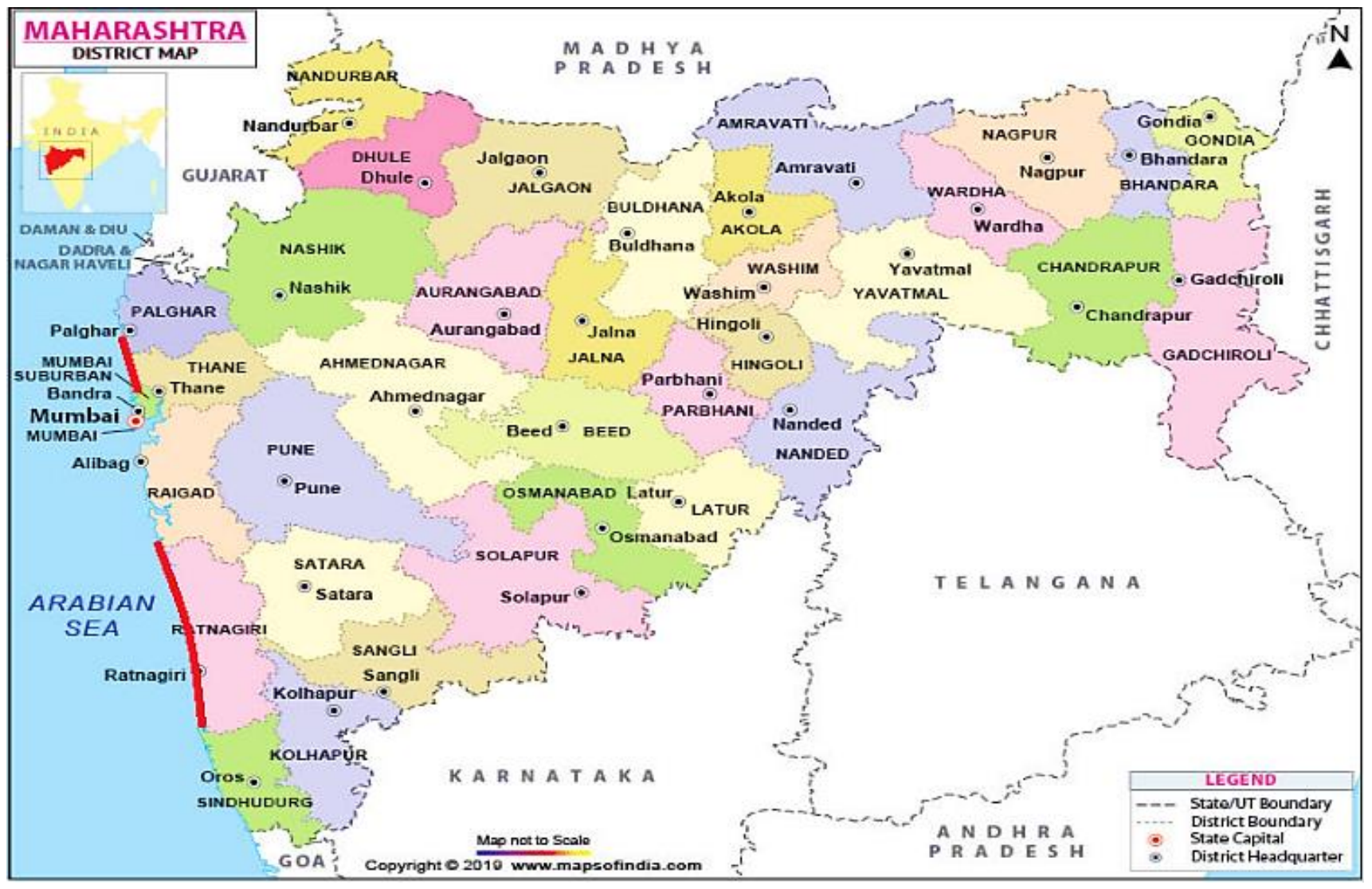

Figure 1 \& 2: Study Areas in Gujarat \& Maharashtra (Shown in Red Boundary), Source: Maps of India

belong to Kutch and Valsad districts of Gujarat and Ratnagiri and nearby villages of Mumbai districts of Maharashtra (Figure $1 \& 2$ ). Demographic data were collected from 954 women aged $40+$ years (considered to have completed their fertility) on fertility (pregnancies, live births etc.) and mortality (still births, abortion, child death before 15 years of age etc.). Ethical clearance was obtained from appropriate authorities prior to the commencement of the study. Subjects were informed about the objectives of the study and written consent was obtained from them.

The selection intensity has been computed by using internationally accepted original method devised by Crow in 1958 and later modified formulae by Johnston \& Keisinger in 1971.

\section{Results and Discussion}

Data on various demographic parameters were collected and tabulated (Table 1). The data involves 954 mothers who experienced 3207 pregnancies during their reproductive life span. Among these pregnancies
3017 were successful birth and 190 were pre-natal deaths. The post-natal death counts 329 of total successful pregnancies. The methodologies devised by Crow (1958) and Johnston \& Kensinger (1971) were used to determine total selection indices. The proportion of pre-reproductive deaths varied from 0.162-0.073 and proportion of pre- embryonic deaths varied from $0.096-0.028$ (Table 3). The proportion of survivor from birth to reproductive age was highest among Bhoi of Maharashtra (0.927) and lowest among Muslim of Gujarat (0.838). Overall the total index of selection was highest (0.617) among the Machhawa of Maharashtra and lowest (0.388) among the Macchiyaras of Gujarat. In Maharashtra the lowest total index of selection was among Bhoi (0.418) and in Gujarat the highest total intensity of selection was among Koli (0.596) (Table 2). Among all these mentioned populations the selection was operating due to fertility component rather than mortality component. The fertility component contributed more than $70 \%$ in total index of selection in all populations, 


\begin{tabular}{|c|c|c|c|c|c|c|c|c|}
\hline 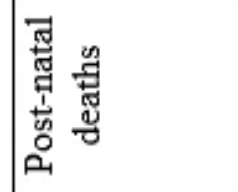 & : & $\infty$ & $m$ m & of & প্ল & 일. & ๆ & 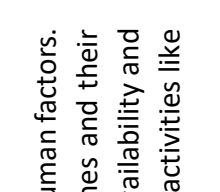 \\
\hline 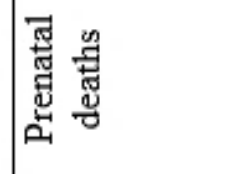 & 이: & 9 & $\begin{array}{rll}\pi & 0 \\
& 0\end{array}$ & $\stackrel{\infty}{\sim}$ & $\beth$ & $\therefore=$ & $m:$ & 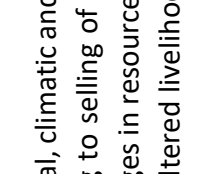 \\
\hline 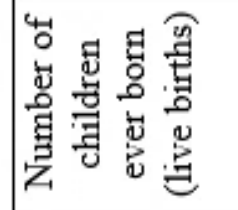 & 究: & స్ & 위류 & $\stackrel{m}{\dddot{f}}$ & $\stackrel{9}{7}$ & $\stackrel{\infty}{m}$ ) & 分 & 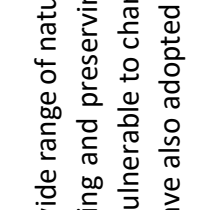 \\
\hline 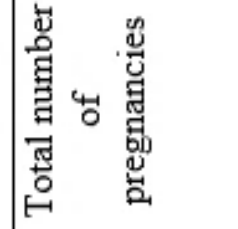 & 害: & 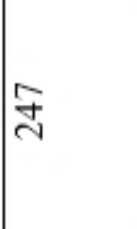 & m̂l & $\hat{n}=$ & $\stackrel{\text { }}{\stackrel{y}{q}}$ & ली & 케 & 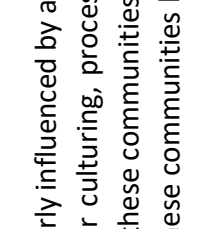 \\
\hline 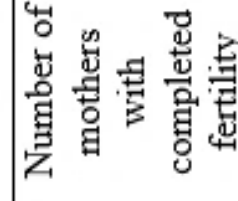 & ? & \pm & 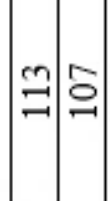 & 의! & ঙ্ণ & $2 \div$ & 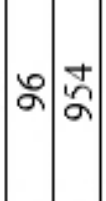 & 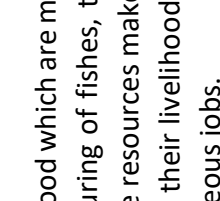 \\
\hline 雚 & : & 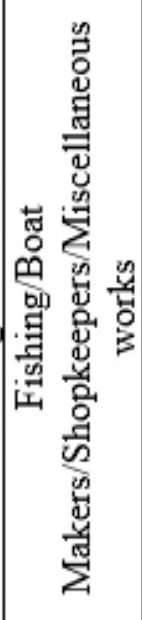 & 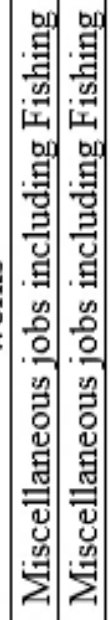 & : & 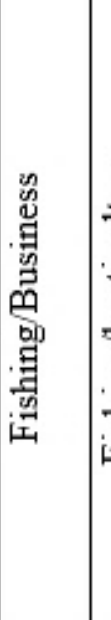 & 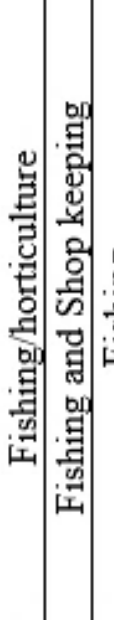 & 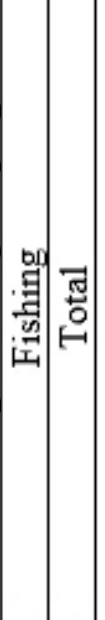 & 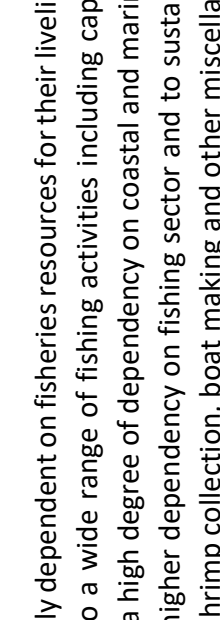 \\
\hline 虽总 & & 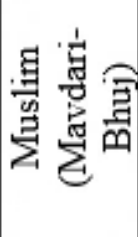 & $:$ & | & 品 & : & $\mid$ & 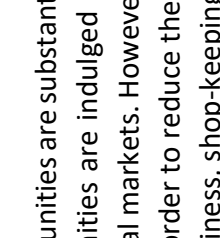 \\
\hline 焉 & $\begin{array}{l}\text { 蘦 } \\
\end{array}$ & & & & & & & 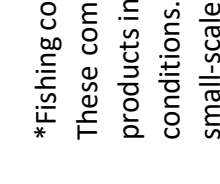 \\
\hline
\end{tabular}




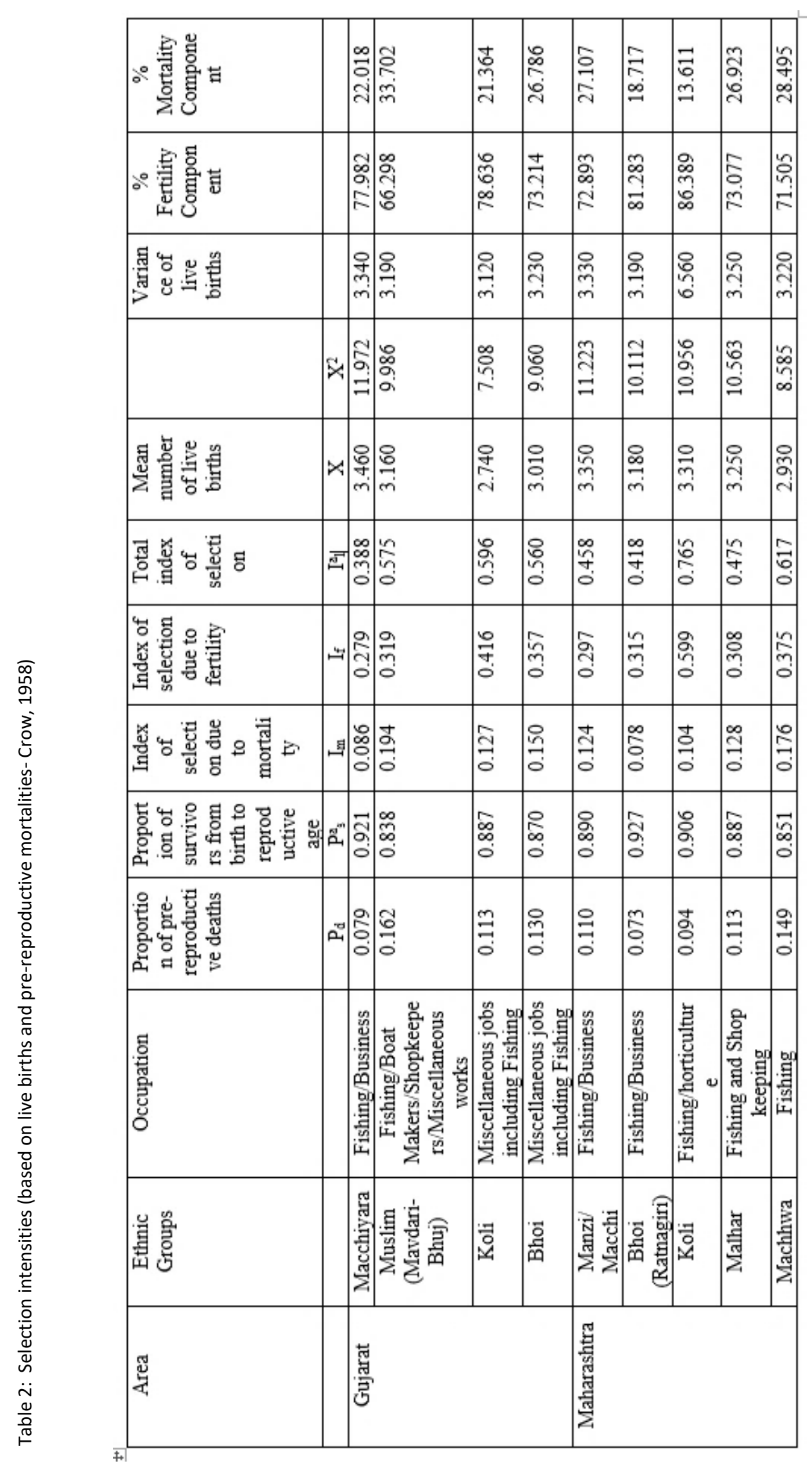




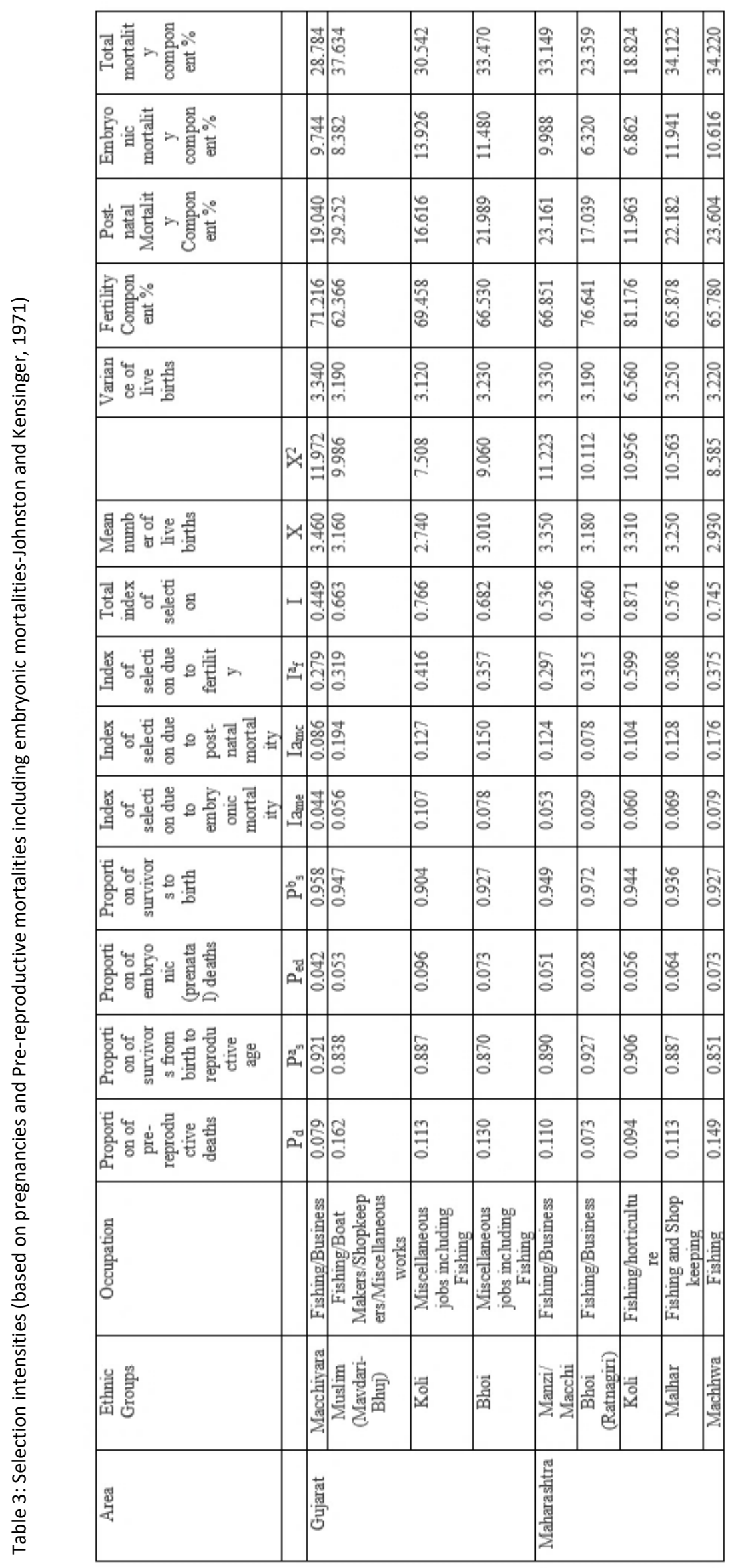


although it varied from 62.37 among Muslim of Gujarat to 81.18 among Koil of Maharashtra. As mentioned in Table-2 the overall contribution of fertility component is $75.70 \%$ while of mortality component is $24.30 \%$. The reduction in mortality component was may be due to diseases occurring among the coastal populations. The total selection index was reported to be moderate among these populations, as average total selection index for Indian population was reported to be 0.585 (Gautam, 2009).

The high post-natal mortality in the studied populations may be due to the poor health care (Shyam et al., 2014) and environment provided to them. Environmental conditions contributing high post-natal mortality include inadequate facilities for proper living and more emphasis on the ante-natal care than post-natal care (Mavalankar et al., 2009). Furthermore, the negligence from various vaccinations, unhealthy post-natal care practices, gender related neglect of healthcare seeking due to high expenditure of specialized healthcare services can also be a cause of this high rate of postnatal mortality (Shah and Dwivedi, 2013; Dabade et al., 2013; Chaudhari and Virmani, 2016).

The contribution of fertility component to total selection index in current study is higher than the earlier study of coastal populations study by Kapoor et al in 2012. Their study among the populations of Goa and Odisha shows the fertility component contribution of $66.23 \%$ while present study estimate is of $69.54 \%$ (Table-3). Similarly, there is a decrease in the embryonic mortality component contribution (9.92\%) as compared to their study (13.95\%) and there is slight increase in the post-natal mortality component contribution (19.82\%earlier to $20.54 \%$-present). Since both the studies were conducted among the coastal populations so the risk on the life must be same through natural calamities, although the quality of life can be affected by their local government agenda or the policies and facilities available to them in last few years. So, the overall increase in fertility component and decrease in embryonic mortality component shows the continuous increase in the health services in the present study area despite the fact that both area differs so, there must be chance that the variations can be area dependent, but if we consider the progress of coastal areas on overall basis then the increase is efficient and valid.

\section{Conclusion}

The study shows that the contribution of fertility component in total selection is more than mortality component. As, this show an inversion from the general past trend of selection among coastal populations and similarity with non-coastal populations. This must be due to improved health care, proper sanitation, reduction or protection from natural hazards etc. Further, a re-analysis of all the studied coastal area after fixed time must be required to trace out the actual selection pattern.

\section{Acknowledgements}

AKK is grateful to University of Delhi for providing financial assistance in the form of DU-DST and R\&D projects under which field work was conducted in various phases in Gujarat and Maharashtra. Authors are also grateful to all the people for their help and support in the conduction of field work.

\section{References}

Chaudhari, S. and Virmani, S. 2016. Knowledge and attitude of postnatal mothers towards neonatal care in a rural area of Maharashtra, India. International Journal of Reproduction, Contraception, Obstetrics and Gynecology, 5(6), 1883-1887.

Crow, F. J. 1958. Some possibilities of measuring selection intensities in man. Hum. Biol. 30: 1-13.

Dabade, K. J., Dabade, S. K. and Khadilkar, H. A. 2013. A study on utilization of maternal health care services in rural area of Aurangabad district, Maharashtra. National Journal of Community Medicine, 4(4), 579-583.

Gautam, R. K. 2009. Opportunity for natural selection among the Indian population: secular trend, covariates and implications. J biosoc Sci. 41: 705-745.

Gautam, R. K. 2009. Opportunity for natural selection among the Indian population: Secular trend, covariates and implications. J Bioscoc sci. 41: 705-745.

Jacquard, A. 1969. Genetique humaine et demographic. Popul. 3: 553-559.

Johnston, F. E. and Kensinger, K. M. 1971. Fertility and mortality differentials and their implications for microevolutionary change among the Cashinahua. Hum. Biol. 43(3): 356-364. 
Jorde, L. B. and Durbize, P. 1986. Opportunity for natural selection in the Utah Mormons. Hum Biol. 58: 97-114.

Kapoor, A. K., Gautam, R. K. and Bhasin, P. 2012. Natural Selection among coastal population of India: Trend and extent. Annals of Human Biology. 39(3): 247-258.

Kapoor, A. K., Kshatriya, G. K. and Kapoor, S. 2003. Fertility and mortality differentials among population groups of the Himalayas. Hum Biol. 75: 729-747.

Lasker, G. W. and Kaplan, B. A. 1995. Demography in biological anthropology human population structure and evolution. Am J Hum Biol. 7: 425:430.

Livingston, F. B. and Spuhler, J. N. 1965. Cultural determinants of natural selection. Int Soc Sci J. 17: 118- 120.

Mavalankar, D. V., Vora, K. S., Ramani, K. V., Raman, P., Sharma, B. and Upadhyaya, M. 2009. Maternal health in Gujarat, India: a case study. Journal of health, population, and nutrition, 27(2), 235.

Nicholls, R. J., Hoozemans, F. M. J. and Marchand, M. 1999. Increasing fold risk and wetland loses due to global sea-level rise: regional and global analyses. Global Environ Change. 9: S69-S87.

Pearson, K., F. R. S. 1912. The intensity of natural selection in man. Proceedings of the Royal Society B. 85 (581):469-476.

Reddy, B. K. C. and Reddy, S. C. Selection Intensity among Reddis and Voddes of Southern Andhra pradesh. Indian National Seminar on Anthropology: Contemporary Challenges and Perspectives a symposium on Human Genetics, Health and Society. SV University, Tirupati, Andhra Pradesh. India, 2004.

Sarkar, N. C., Barua, S. and Varte, R. T. 1994. Opportunity of selection in the Champ of Lakhimpur District, Assam, India. J Hum Ecol. 5: 217-220.

Shah, B. D. and Dwivedi, L. K. 2013. Newborn care practices: A case study of tribal women, Gujarat. Health, 2013.

Shyam, S. S., Narayanakumar, R., Katiha, P. K., Krishnan, M., Barik, N., Gopal, N., Biradar, R.S., Sharma, A. and Ponnusami, K. 2014. Marine Capture Fisheries. Central Marine Fisheries Research Institute, Kerala. http://eprints.cmfri.org.in/10321/1/2.pdf

Singh, K. and Kapoor, A. K. 2015. Natural Selection Intensity in Indian Population - An Overview. Ame Inter J. of contemporary Scie. Res. 2(4): 1-8.

Spuhler, J. N. 1962. Empirical studies on quantitative human genetics. Proceedings of UN/WHO seminar on the use of vital health statistics for genetic and radiation studies. New York: United Nations.

Tripp-Reimer, T. 1980. Genetic demography of urban Greek immigrant community. Hum Biol. 52: 255-267.

Varekamp, J.C. 1999. Modern rates of sea level rise exceeds average rate of last 2000 years, Available online at http://www.ncdc.noaa.gov/ogp/papers/varekamp.html, accessed January 27, 2018. 